\title{
The effects of heatwaves and cold spells on patients admitted with acute ischemic stroke
}

\author{
Xuemei Qi ${ }^{1}$, Zhongyan Wang ${ }^{2}$, Xiaoshuang Xia ${ }^{1}$, Juanjuan Xue ${ }^{1}$, Yumeng Gu ${ }^{1}$, Suqin Han ${ }^{3}$, Qing Yao ${ }^{3}$, \\ Ziying Cai ${ }^{3}$, Xiaojia Wang ${ }^{3}$, Lin Wang ${ }^{2}$, Sean X. Leng ${ }^{4}$, Xin $\mathrm{Li}^{1} \wedge$ \\ ${ }^{1}$ Department of Neurology, The Second Hospital of Tianjin Medical University, Tianjin, China; ${ }^{2}$ Department of Geriatrics, The Second Hospital \\ of Tianjin Medical University, Tianjin, China; ${ }^{3}$ Tianjin Environmental Meteorology Center, Tianjin, China; ${ }^{4}$ Division of Geriatric Medicine and \\ Gerontology, School of Medicine, Johns Hopkins University, Baltimore, MD, USA \\ Contributions: (I) Conception and design: X Li, SX Leng; (II) Administrative support: None; (III) Provision of study materials or patients: X Li, S \\ Han; (IV) Collection and assembly of data: X Qi, Z Wang, X Xia, J Xue, Y Gu, Q Yao, Z Cai, X Wang; (V) Data analysis and interpretation: X Qi, X \\ Xia, L Wang; (VI) Manuscript writing: All authors; (VII) Final approval of manuscript: All authors. \\ Correspondence to: Sean X. Leng. Division of Geriatric Medicine and Gerontology, Johns Hopkins University School of Medicine, 5501 Hopkins \\ Bayview Circle, Baltimore, MD 21224, USA. Email: sleng1@jhmi.edu; Xin Li. Department of Neurology, The Second Hospital of Tianjin Medical \\ University, 23 Pingjiang Road, Tianjin 300211, China. Email: lixinsci@126.com.
}

Background: This study aimed to explore the effects of heatwaves and cold spells on blood pressure, thrombus formation, and systemic inflammation at admission in patients with ischemic stroke.

Methods: Data of patients with ischemic stroke who were admitted to the Second Hospital of Tianjin Medical University between May 2014 and March 2019 were reviewed, along with meteorological data from the same time period. A total of 806 clinically confirmed patients with ischemic stroke (34-97 years old) were included in the final analysis. Heatwaves and cold spells were defined as $\geq 2$ consecutive days with average temperature $>95^{\text {th }}$ percentile (May-August) and $<5^{\text {th }}$ percentile (November-March), respectively. Coagulation parameters, inflammation indices, blood pressure, and neurological impairment were evaluated within 24 hours of admission. General linear and logistic regression models were created to investigate the relationships of heatwaves and cold spells with the examination results of patients with ischemic stroke at admission.

Results: After adjustment for potential environmental confounders, heatwaves were positively associated with high systolic blood pressure $(\mathrm{SBP})(\beta=8.693, \mathrm{P}=0.019)$, diastolic blood pressure (DBP) $(\beta=3.665$, $\mathrm{P}=0.040)$, reduced thrombin time $(\mathrm{TT})(\beta=-0.642, \mathrm{P}=0.027)$, and activated partial thromboplastin time (APTT) $(\beta=-1.572, \mathrm{P}=0.027)$ in ischemic stroke patients at admission. Cold spells were positively associated with high SBP $(\beta=5.277, \mathrm{P}=0.028)$, DBP $(\beta=4.672, \mathrm{P}=0.012)$, fibrinogen $(\beta=0.315, \mathrm{P}=0.011)$, globulin $(\beta=1.523, \mathrm{P}=0.011)$, and reduced TT $(\beta=-0.784, \mathrm{P}<0.001)$ and APTT $(\beta=-1.062, \mathrm{P}=0.024)$. Cold spells were also associated with a higher risk of respiratory infection [odds ratio $(\mathrm{OR})=2.677, \mathrm{P}=0.001$ ].

Conclusions: Exposure to heatwaves or cold spells was associated with blood pressure and coagulation at admission in patients with ischemic stroke. Cold spells also resulted in higher levels of inflammation. These findings suggest that changes in coagulation, blood pressure, and inflammation may be the potential biological mechanisms underlying the cerebrovascular effects of exposure to extreme temperatures.

Keywords: Ischemic stroke; cold spell; heatwave

Submitted May 26, 2020. Accepted for publication Nov 20, 2020.

doi: 10.21037/atm-20-4256

View this article at: http://dx.doi.org/10.21037/atm-20-4256

^ ORCID: 0000-0002-2977-5075. 


\section{Introduction}

Stroke is a leading cause of disability and mortality in China $(1,2)$. There are many contributing factors to the increasing number of ischemic strokes. Traditional cardiovascular risk factors contribute to the occurrence of stroke and fundamentally explain the etiology and prognosis of ischemic stroke; however, environmental factors should not be ignored, and they may contribute to the pathogenesis of stroke.

Climate change is considered to be the biggest threat to human health in the $21^{\text {st }}$ century. Extreme temperature events, including heatwaves and cold spells, are becoming more frequent and intense as the climate changes (3). Many epidemiological studies have reported associations between air temperature and the occurrence of stroke, although the exact findings of studies to date have been inconsistent $(4,5)$. A strong association between extreme temperatures and stroke mortality has been reported (6-11), and extreme temperatures have also been shown to increase the risk of hospitalization due to ischemic stroke $(10,12-14)$, as reported in different climatic regions of China (15-18). A recent study in Hefei, China suggested that cold spells defined by percentile were associated with an increased risk of hospitalization for ischemic stroke (19). However, the biological mechanisms underlying the effects of extreme temperatures on patients with ischemic stroke are not well understood.

Vasoconstriction, thrombosis, and systemic inflammation are among the mechanisms proposed to be involved in the initiation and aggravation of cardio-cerebrovascular events. For instance, elevated levels of fibrinogen and plasma C-reactive protein (CRP) were found to be associated with an increased risk and unfavorable prognosis of ischemic stroke (20). Furthermore, a few studies have reported that changes in temperature affected a number of cerebrovascular risk factors and biomarkers, such as blood pressure, fibrinogen, and CRP $(21,22)$. However, most of these studies were conducted on patients with diabetes, cardiovascular, and pulmonary diseases, and the results have been inconsistent. Moreover, these associations have rarely been examined in patients with ischemic stroke. A recent study in subtropical zones of southern China found that the blood pressure, coagulation factors, and neurological impairment of patients with ischemic stroke who had been exposed to average temperatures $<13{ }^{\circ} \mathrm{C}$ differed from those of patients admitted during warm spells in winter (23). However, studies about the potential effects of both heatwaves and cold spells on the mechanistic roles of thrombus formation, systemic inflammation, and blood pressure in ischemic stroke are scarce.

Therefore, our study aimed to explore the effects of heatwaves and cold spells on risk factors, thrombus formation, systemic inflammation, and degree of neurological impairment in patients with ischemic stroke admitted to the Second Hospital of Tianjin Medical University from 2014 to 2019.

We present the following article in accordance with the STrengthening the Reporting of OBservational studies in Epidemiology (STROBE) reporting checklist (available at http://dx.doi.org/10.21037/atm-20-4256).

\section{Methods}

\section{Study participants}

We performed a retrospective study on acute ischemic patients who were admitted to the stroke unit of the Second Hospital of Tianjin Medical University (Tianjin, China) between May 2014 and March 2019. Patients who were aged $\geq 34$ years old and admitted within 72 hours of symptom onset were included. Ischemic stroke was diagnosed by neurologists according to the criteria of the $10^{\text {th }}$ version of the International Classification of Diseases (I63.0). Magnetic resonance imaging (MRI) and/or computed tomography (CT) was performed on all patients after admission to confirm the diagnosis of acute ischemic stroke. The neurologists used the National Institutes of Health Stroke Scale (NIHSS) to evaluate neurological deficits within 8 hours of admission. Patients who met any of the following criteria were excluded: (I) NIHSS score $\leq 1$ at admission ( $\mathrm{n}=230)$; (II) major systemic diseases including malignant tumor $(\mathrm{n}=22)$, kidney disease $(\mathrm{n}=14)$, liver disease $(\mathrm{n}=10)$, rheumatic disease $(\mathrm{n}=8)$, blood disease including anemia and thrombocytopenia $(n=3)$, mental health disorder $(\mathrm{n}=3)$, systemic lupus disease $(\mathrm{n}=1)$, and cognitive impairment $(\mathrm{n}=1)$; (III) incomplete data $(\mathrm{n}=15)$. Finally, 806 acute ischemic stroke patients with were included in the analysis, with 434 patients admitted between May and August and 372 patients admitted between November and March (Figure 1).

This study was conducted in accordance with the Declaration of Helsinki (as revised in 2013). The study was approved by the Ethics Committee of the Second Hospital of Tianjin Medical University (KY2020K142), and the requirement for individual consent was waived due to the 


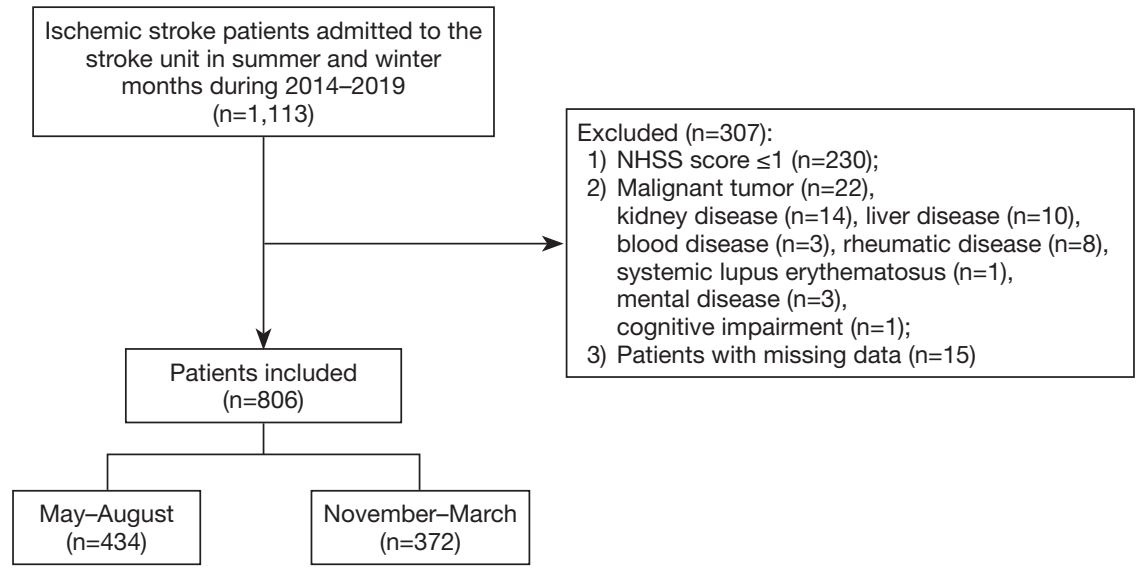

Figure 1 Flowchart of the study. NIHSS, National Institutes of Health Stroke Scale.

study's retrospective nature.

\section{Meteorological data}

Tianjin $\left(38^{\circ} 34^{\prime} \mathrm{N}-40^{\circ} 15^{\prime} \mathrm{N}, 116^{\circ} 43^{\prime} \mathrm{E}-118^{\circ} 04^{\prime} \mathrm{E}\right)$, a municipality in northern China, is located in a warmtemperate, semi-humid, monsoon climate zone, with hot summers and cold winters. The Tianjin Meteorological Bureau provided the meteorological observations and air pollution data from during the period of study, including the daily mean level of air temperature, barometric pressure, relative humidity, wind speed, and air quality index (AQI, which was used as a measure of air pollution calculated according to the daily level of PM2.5, $\mathrm{PM} 10, \mathrm{SO}_{2}, \mathrm{NO}_{2}, \mathrm{O}_{3}$, and $\mathrm{CO}$ ).

\section{Definition of heatwaves and cold spells}

There is no global standard definition for heatwave or cold spell; they are either defined as a few consecutive days with temperatures above or below a certain threshold, or are defined using exact temperature thresholds $(7,19)$. Many studies related to the health effects of extreme temperatures have shown that defining a heatwave or cold spell by the percentile method might be more appropriate than using the absolute threshold $(7,24)$. The mean daily temperature, which could reflect the average exposure level of the day, was deemed appropriate for use as exposure indices considering that the maximum and the minimum daily temperature only reflected a short period of exposure (19). According to previous studies, heatwaves and cold spells are restricted to summer (May to August) and winter seasons
(November to March), respectively $(3,7,19)$. In our study, a heatwave was defined as a daily mean temperature $>95^{\text {th }}$ percentile $\left(31.7^{\circ} \mathrm{C}\right)$ and duration $\geq 2$ days from May to August.

Previous studies have also suggested that the health effects of heatwaves are usually immediate and last for 3-4 days, although they may continue for as long as 7 days in some cases $(6-8,25)$. Therefore, we defined patients admitted during heatwaves and the following consecutive 7 days as the heatwave group; otherwise, patients were assigned to the non-heatwave group. A cold spell was defined as a daily mean temperature $<5^{\text {th }}$ percentile $\left(-3.7^{\circ} \mathrm{C}\right)$ and duration $\geq 2$ days from November to March in the following year $(3,8,19,26)$. The health effects of cold temperature can last longer than those of heat, lasting for as long as 2 weeks (6). Therefore, patients admitted during cold spells and the following consecutive 14 days were defined as the cold-spell group; otherwise, patients were assigned to the non-coldspell group (23).

\section{Patient assessments}

Patient medical records were reviewed for demographic characteristics and clinical history. Blood pressure [including systolic blood pressure (SBP) and diastolic blood pressure (DBP)] was measured within 8 hours of hospitalization. Neurological impairment of patients was assessed using the NIHSS. Measurements of blood cell counts (leukocytes, erythrocytes, and platelets), coagulation factors [thromboplastin time (TT), prothrombin time (PT), activated partial thromboplastin time (APTT), fibrinogen, and D-dimer], and inflammation indices (high-sensitivity 


\section{Page 4 of 12}

C-reactive protein (hs-CRP), albumin, and globulin) were determined within 24 hours of admission. The presence of respiratory infection was also recorded from the medical records.

\section{Statistical analysis}

Differences in demographic characteristics, medical history, blood pressure, coagulation factors, inflammatory indices, and the degree of neurological impairment were analyzed among patients in heatwave and cold-spell groups. Continuous variables were described as the mean \pm standard deviation or median (interquartile range). Categorical variables were presented as counts (percentage). The $t$-test was used for continuous variables with normal distribution and the Mann-Whitney-Wilcoxon test for continuous variables without normal distribution. The Chi-square test was used for categorical variables (23). General linear models were used to analyze the association between extreme temperatures and the continuous variables that were statistically significant in the inter-group comparison. Binary logistic regression was used to study the association between cold spells and respiratory infection. The $\beta$ coefficient or the odds ratio (OR) and the corresponding $95 \%$ confidence interval (CI) were used to describe the effect estimates of heatwaves and cold spells. Model 1 was unadjusted, and model 2 was adjusted for air pressure, relative humidity, wind speed, and AQI. A two-tailed $\mathrm{P}$ value $<0.05$ was considered to be statistically significant. All analyses were performed using the statistical software SPSS 25.0 (IBM Corp., Armonk, NY, USA).

\section{Results}

\section{Summary of meteorological variables}

During the study period, there were 7 heatwaves of 2-4 days in duration from May to August. The lowest maximum temperature and the highest maximum temperature were 35.4 and $39.6{ }^{\circ} \mathrm{C}$, respectively. During the study period, 10 cold spells lasting for 2-7 days were recorded from November to March. The lowest minimum and the highest minimum temperature were -14.5 and $-5.6{ }^{\circ} \mathrm{C}$, respectively. The results also showed that heatwaves and cold spells have become more frequent since 2018 (Table 1).

A summary of the daily mean temperature, air pressure, relative humidity, and wind speed for the heatwave group, non-heatwave group, cold-spell group, and non-cold-spell group is shown in Table 2. Patients in the heatwave group were exposed to a much higher temperature $\left(30.1 \pm 2.7^{\circ} \mathrm{C}\right)$ than those in the non-heatwave group $\left(26.0 \pm 3.5^{\circ} \mathrm{C}\right)$, and patients in the cold-spell group were exposed to a much lower temperature $\left(-0.7 \pm 4.5^{\circ} \mathrm{C}\right)$ than those in the non-coldspell group $\left(4.7 \pm 4.9^{\circ} \mathrm{C}\right)$.

\section{Patient demographic characteristics and medical history}

A total of 806 patients (mean age, $70.9 \pm 11.5$ years old) with acute ischemic stroke were included in the final analysis (Figure 1), including 550 (68.2\%) men and 256 (31.8\%) women. A total of 434 patients were admitted to hospital from May to August and were divided into the heatwave group $(n=54)$ and the non-heatwave group $(n=380)$. A total of 372 patients were admitted from November to March in the following year and were divided into the cold-spell group ( $\mathrm{n}=96)$ and non-cold-spell group $(\mathrm{n}=276)$ (Figure 1). The baseline demographics and clinical characteristics of acute ischemic stroke patients stratified by exposure to heatwaves or cold spells are compared in Table 3. The noncold-spell group had more patients with diabetes (116, $42.0 \% ; \mathrm{P}=0.001)$ and a history of stroke $(78,28.3 \% ; \mathrm{P}=0.02)$. There was no significant difference among the patients with regard to age, sex, smoking, drinking, or medical history including hypertension, hypercholesterolemia, coronary heart disease, and atrial fibrillation $(\mathrm{P}>0.05)$.

\section{The effects of heatwaves on patients with acute ischemic stroke}

At admission, the TT and APTT in the heatwave group were significantly shorter than those in the non-heatwave group (TT, $18.3 \pm 1.0$ vs. $18.9 \pm 1.5 \mathrm{~s}, \mathrm{P}=0.02$; APTT, $23.9 \pm 3.2$ vs. $25.5 \pm 3.7 \mathrm{~s}, \mathrm{P}=0.02)$. There was no difference between the two groups concerning other coagulation factors, such as platelet count, PT, D-dimer, and fibrinogen level. The blood pressure of the patients exposed to heatwaves was elevated compared to that of the non-heatwave group (SBP: $159.4 \pm 24.0$ vs. $151.0 \pm 24.6 \mathrm{mmHg}, \mathrm{P}=0.02$; DBP: $87.6 \pm 13.3$ vs. $83.9 \pm 11.6 \mathrm{mmHg}, \mathrm{P}=0.04)$. However, the proportion of patients with respiratory infection and inflammatory indices, including white blood cell count, hs-CRP, albumin, and globulin levels, did not differ between the two groups. Additionally, no inter-group differences were found in red blood cell count or NIHSS score at admission (Table 4). After adjustment for air pressure, relative humidity, wind speed, and AQI, the general linear models demonstrated 
Table 1 Characteristics of heat waves and cold spells in Tianjin, China during 2013.05-2019.03

\begin{tabular}{|c|c|c|c|c|c|c|}
\hline $\begin{array}{l}\text { Extreme } \\
\text { temperatures }\end{array}$ & Date of start & Duration (days) & $\begin{array}{l}\text { Lowest minimum } \\
\text { temperature }\left({ }^{\circ} \mathrm{C}\right)\end{array}$ & $\begin{array}{l}\text { Highest minimum } \\
\text { temperature }\left({ }^{\circ} \mathrm{C}\right)\end{array}$ & $\begin{array}{l}\text { Lowest maximum } \\
\text { temperature }\left({ }^{\circ} \mathrm{C}\right)\end{array}$ & $\begin{array}{l}\text { Highest maximum } \\
\text { temperature }\left({ }^{\circ} \mathrm{C}\right)\end{array}$ \\
\hline \multirow[t]{4}{*}{ Heat waves ${ }^{a}$} & June 19, 2014 & 3 & 27.7 & 28.7 & 35.4 & 36.4 \\
\hline & June 16, 2017 & 2 & 25.9 & 26.0 & 37.2 & 37.9 \\
\hline & July 19, 2018 & 3 & 29.7 & 29.9 & 36.4 & 37.6 \\
\hline & July 31, 2018 & 4 & 28.6 & 29.5 & 35.7 & 37.9 \\
\hline \multirow[t]{7}{*}{ Cold spells $^{b}$} & November 24, 2015 & 4 & -8.5 & -6.2 & -3.7 & -1.3 \\
\hline & January 22, 2018 & 7 & -11.7 & -7.7 & -5.4 & -2.9 \\
\hline & December 07, 2018 & 2 & -8.1 & -6.8 & -4.8 & -2 \\
\hline & December 27, 2018 & 7 & -10.4 & -7.4 & -4.3 & 1.8 \\
\hline & January 1, 2019 & 2 & -10.2 & -9.2 & 0.9 & 1.8 \\
\hline & January 15, 2019 & 2 & -8.8 & -8.0 & 2.6 & 2.8 \\
\hline & February 07, 2019 & 4 & -9.8 & -8.2 & -2.8 & -0.6 \\
\hline
\end{tabular}

a , a heatwave was defined as daily mean temperature $>95^{\text {th }}$ percentile $\&$ duration $\geq 2$ days from May to August; ${ }^{b}$, a cold spell was defined as daily mean temperature $<5^{\text {th }}$ percentile \& duration $\geq 2$ days from November to March.

that heatwaves were associated with higher SBP $(\beta=8.693$, 95\% CI: $1.448-15.928, P=0.019)$ and DBP $(\beta=3.665,95 \%$ CI: $0.168-7.161, \mathrm{P}=0.040)$, as well as lower TT $(\beta=-0.642$, 95\% CI: -1.209 to -0.076$], \mathrm{P}=0.027)$ and APTT $(\beta=-1.572$, 95\% CI: -2.966 to $-0.179, \mathrm{P}=0.027$ ) (Table 5).

\section{The effects of cold spells on patients with acute ischemic stroke}

Cold spells exerted more remarkable influences on acute ischemic stroke patients. Both the TT and APTT of the cold-spell group were shorter than those of the non-coldspell group $(\mathrm{P}<0.05)$. The fibrinogen level was elevated in the cold-spell group $(3.5 \pm 1.0$ vs. $3.2 \pm 0.9 \mathrm{~g} / \mathrm{L}, \mathrm{P}=0.04)$. No difference was found with regard to platelet count, PT, or D-dimer between the two groups. The proportion of patients with respiratory infection was higher in the coldspell group $(30.2 \%$ vs. $13.8 \%, \mathrm{P}<0.01)$. The inflammatory indices were also elevated among the cold-spell group, with an increased white blood cell count and globulin level, and a decreased rate of albumin/globulin $(\mathrm{A} / \mathrm{G})(\mathrm{P}<0.05)$. However, the hs-CRP showed no difference between the two groups. Patients exposed to cold spells also had higher blood pressure at admission than those in the noncold-spell group (SBP: $157.0 \pm 20.4$ vs. $151.1 \pm 18.1 \mathrm{mmHg}$, $\mathrm{P}=0.01$; DBP: $88.8 \pm 14.4$ vs. $84.3 \pm 13.9 \mathrm{mmHg}, \mathrm{P}=0.01$ ). No difference was found in blood electrolyte levels or NIHSS score at admission between the cold-spell group and noncold-spell group (Table 4). After adjustment for air pressure, relative humidity, wind speed, and AQI, the general linear models showed that cold spells were associated with higher SBP ( $\beta=5.277,95 \%$ CI: 0.586-9.967, $\mathrm{P}=0.028)$, DBP ( $\beta=4.672,95 \%$ CI: $1.023-8.320, P=0.012)$, fibrinogen $(\beta=0.315,95 \%$ CI: $0.074-0.556, P=0.011)$, and globulin $(\beta=1.523,95 \%$ CI: 0.354-2.692, $\mathrm{P}=0.011)$. An association was also observed between cold spells and increased white blood cell count ( $\beta=0.625,95 \%$ CI: 0.097-1.153, $\mathrm{P}=0.020$ ); however, the relationship was not statistically significant after adjustment for all confounders. In addition, after adjustment for air pressure, relative humidity, wind speed, 
Table 2 Summary of the daily mean meteorological parameters for the heat-wave group, non-heat-wave group, cold spell group and non-cold spell group of patients with ischemic stroke

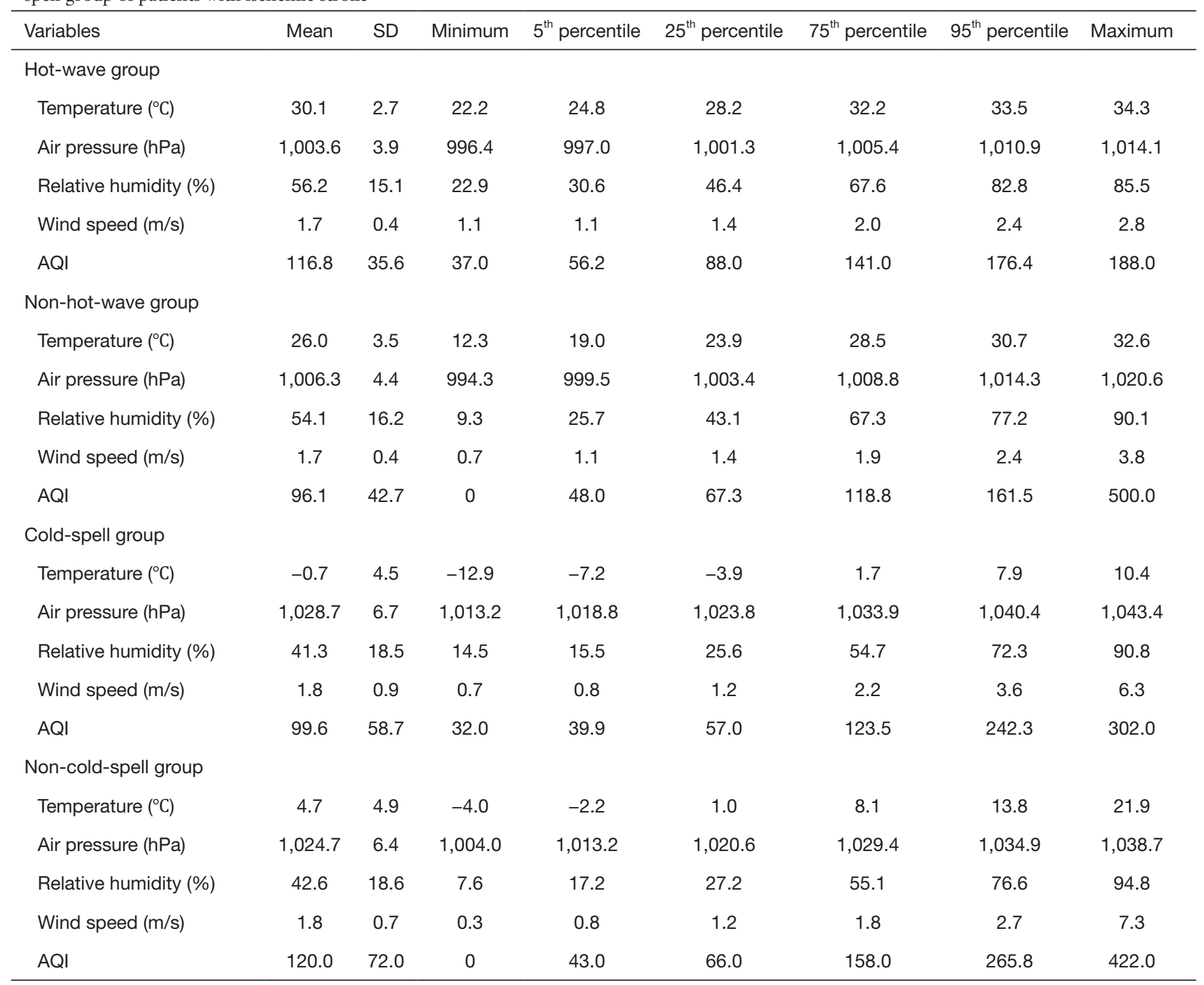

$\mathrm{SD}$, standard deviation; AQI, air quality index.

and AQI, associations between cold spells and shorter TT ( $\beta=-0.784,95 \%$ CI: -1.111 to $-0.457, \mathrm{P}<0.001)$ and APTT $(\beta=-1.062,95 \%$ CI: -1.983 to $-0140, \mathrm{P}=0.024)$ were also apparent. Cold spells were also found to be a risk factor for respiratory infection (adjusted OR $=2.677,95 \%$ CI: 1.462 4.901, $\mathrm{P}<0.001)($ Table 6).

\section{Discussion}

This study revealed that heatwaves and cold spells had effects on acute ischemic stroke patients, and cold spells were shown to exert a more remarkable influence.
Heatwaves and cold spells were associated with blood pressure and coagulation factors. Besides, a higher proportion of patients exposed to cold spells had respiratory infection and elevated inflammatory indices at admission. These findings indicate the possible biological mechanisms underlying the cerebrovascular effects of extreme temperatures.

Epidemiological studies have found that exposure to extreme temperatures including heatwaves and cold spells increases the risk of ischemic stroke hospitalization and mortality (15-18). However, the biological mechanisms underlying these associations have not been fully elucidated. 
Table 3 Comparison of the baseline demographics and clinical characteristics of patients with ischemic stroke stratified by heat wave or cold spell

\begin{tabular}{|c|c|c|c|c|c|c|}
\hline Parameters & $\begin{array}{l}\text { Hot-wave group } \\
\qquad(n=54)\end{array}$ & $\begin{array}{l}\text { Non-hot-wave group } \\
\qquad(\mathrm{n}=380)\end{array}$ & $P$ value & $\begin{array}{l}\text { Cold-spell group } \\
\qquad(\mathrm{n}=96)\end{array}$ & $\begin{array}{l}\text { Non-cold-spell group } \\
\qquad(\mathrm{n}=276)\end{array}$ & $P$ value \\
\hline Age (mean $\pm S D)$ & $71.4 \pm 10.8$ & $70.5 \pm 11.4$ & 0.56 & $70.7 \pm 10.9$ & $71.6 \pm 11.9$ & 0.51 \\
\hline Smoking, $\mathrm{n}(\%)$ & $21(38.9)$ & $120(31.6)$ & 0.28 & $29(30.2)$ & $96(34.8)$ & 0.41 \\
\hline Drinking, $\mathrm{n}(\%)$ & $14(25.9)$ & $70(18.4)$ & 0.19 & $23(24.0)$ & $58(21.0)$ & 0.55 \\
\hline Diabetes, n (\%) & $17(31.5)$ & $115(30.3)$ & 0.86 & $22(22.9)$ & $116(42.0)$ & $0.001^{\star \star}$ \\
\hline Hypercholesterolemia, n (\%) & $12(22.2)$ & $75(19.7)$ & 0.67 & $31(32.3)$ & $97(35.1)$ & 0.61 \\
\hline Coronary heart disease, n (\%) & $11(20.4)$ & $110(28.9)$ & 0.19 & $26(27.1)$ & $93(33.7)$ & 0.23 \\
\hline
\end{tabular}

*, $\mathrm{P}<0.05 ;{ }^{* *}, \mathrm{P}<0.01 . \mathrm{SD}$, standard deviation.

Table 4 Comparison of laboratory data, NIHSS score, hospitalization time and infection of acute ischemic stroke patients stratified by heat wave or cold spell

\begin{tabular}{|c|c|c|c|c|c|c|}
\hline Parameters & $\begin{array}{l}\text { Hot-wave group } \\
\qquad(n=54)\end{array}$ & $\begin{array}{l}\text { Non-hot-wave group } \\
\qquad(\mathrm{n}=380)\end{array}$ & $P$ value & $\begin{array}{l}\text { Cold-spell group } \\
\qquad(n=96)\end{array}$ & $\begin{array}{l}\text { Non-cold-spell group } \\
\qquad(\mathrm{n}=276)\end{array}$ & $P$ value \\
\hline WBC count $\left(10^{9} / \mathrm{L}\right)$, mean \pm SD & $7.3 \pm 1.8$ & $7.6 \pm 2.9$ & 0.62 & $7.6 \pm 2.4$ & $6.9 \pm 2.0$ & $0.02^{*}$ \\
\hline Platelet count $\left(10^{9} / \mathrm{L}\right)$, mean $\pm \mathrm{SD}$ & $206.8 \pm 64.4$ & $222.7 \pm 64.9$ & 0.18 & $207.2 \pm 49.4$ & $213.5 \pm 55.7$ & 0.36 \\
\hline$\Pi \mathrm{T}(\mathrm{s})$, mean $\pm \mathrm{SD}$ & $18.3 \pm 1.0$ & $18.9 \pm 1.5$ & $0.02^{*}$ & $17.6 \pm 1.0$ & $18.4 \pm 1.3$ & $<0.01^{\star *}$ \\
\hline $\mathrm{APTT}(\mathrm{s})$, mean $\pm \mathrm{SD}$ & $23.9 \pm 3.2$ & $25.5 \pm 3.7$ & $0.02^{*}$ & $24.4 \pm 3.2$ & $25.4 \pm 3.6$ & $0.03^{*}$ \\
\hline Fibrinogen $(\mathrm{g} / \mathrm{L})$, mean $\pm \mathrm{SD}$ & $3.2 \pm 1.0$ & $3.3 \pm 1.0$ & 0.41 & $3.5 \pm 1.0$ & $3.2 \pm 0.9$ & $0.04^{*}$ \\
\hline D-dimer (mg/L), median (IQR) & $0.6(0.3-1.2)$ & $0.5(0.3-0.9)$ & 0.12 & $0.5(0.4-1.2)$ & $0.4(0.3-1.1)$ & 0.31 \\
\hline hs-CRP (mg/L), median (IQR) & $3.4(1.1-6.2)$ & $2.9(1.5-6.7)$ & 0.77 & $5.0(1.5-10.9)$ & $3.0(1.1-9.3)$ & 0.32 \\
\hline Respiratory infection, n (\%) & $9(16.7)$ & $49(12.9)$ & 0.45 & $29(30.2)$ & $38(13.8)$ & $<0.01^{\star *}$ \\
\hline $\mathrm{SBP}(\mathrm{mmHg})$, mean $\pm \mathrm{SD}$ & $159.4 \pm 24.0$ & $151.0 \pm 24.6$ & $0.02^{*}$ & $157.0 \pm 20.4$ & $151.1 \pm 18.1$ & $0.01^{*}$ \\
\hline $\mathrm{DBP}(\mathrm{mmHg})$, mean $\pm \mathrm{SD}$ & $87.6 \pm 13.3$ & $83.9 \pm 11.6$ & $0.04^{*}$ & $88.8 \pm 14.4$ & $84.3 \pm 13.9$ & $0.01^{*}$ \\
\hline NIHSS score, median [IQR] & $4[2-6.5]$ & $4[3-8]$ & 0.14 & $4[3-7.5]$ & $4[3-7]$ & 0.90 \\
\hline
\end{tabular}

*, $\mathrm{P}<0.05$; ** $\mathrm{P}<0.01$. SD, standard deviation; IQR, interquartile range; WBC, white blood cell; RBC, red blood cell; TT, thrombin time; PT, prothrombin time; APTT, activated partial thromboplastin time; A/G, rate of albumin/globulin; hs-CRP, hypersensitive C-reactive protein; SBP, systolic blood pressure; DBP, diastolic blood pressure; NIHSS, National Institutes of Health Stroke Scale. 
Table 5 Estimates of effects of heat waves on blood pressure and coagulation factors in the general linear model

\begin{tabular}{|c|c|c|c|c|}
\hline $\begin{array}{l}\text { Dependent } \\
\text { variable }\end{array}$ & \multicolumn{2}{|c|}{ Model 1} & \multicolumn{2}{|c|}{ Model 2} \\
\hline SBP & $8.455(1.385,15.524)$ & $0.019^{\star}$ & $8.693(1.448,15.928)$ & $0.019^{*}$ \\
\hline DBP & $3.678(0.264,7.092)$ & $0.035^{\star}$ & $3.665(0.168,7.161)$ & $0.040^{*}$ \\
\hline$\pi$ & $-0.628(-1.173,-0.083)$ & $0.024^{*}$ & $-0.642(-1.209,-0.076)$ & $0.027^{\star}$ \\
\hline
\end{tabular}

* $\mathrm{P}<0.05$. Model 1 was unadjusted; Model 2 was further adjusted for air pressure, relative humidity, wind speed and air quality index. $\mathrm{Cl}$, confidential interval; SBP, systolic blood pressure; DBP, diastolic blood pressure; TT, thrombin time; APTT, activated partial thromboplastin time.

Table 6 Estimates of effects of cold spell on blood pressure, inflammation and coagulation factors

\begin{tabular}{|c|c|c|c|c|c|c|c|c|}
\hline \multirow{3}{*}{ Dependent variable } & \multicolumn{4}{|c|}{ General linear model } & \multicolumn{4}{|c|}{ Logistic regression } \\
\hline & \multicolumn{2}{|c|}{ Model 1} & \multicolumn{2}{|c|}{ Model 2} & \multicolumn{2}{|c|}{ Model 1} & \multicolumn{2}{|c|}{ Model 2} \\
\hline & $\begin{array}{c}\beta \text { coefficient } \\
(95 \% \mathrm{Cl})\end{array}$ & $P$ value & $\begin{array}{c}\beta \text { coefficient } \\
(95 \% \mathrm{Cl})\end{array}$ & $P$ value & OR (95\% Cl) & $P$ value & OR $(95 \% \mathrm{Cl})$ & $P$ value \\
\hline SBP & $\begin{array}{c}5.860 \\
(1.250,10.471)\end{array}$ & $0.013^{*}$ & $\begin{array}{c}5.277 \\
(0.586,9.967)\end{array}$ & $0.028^{*}$ & - & - & - & - \\
\hline$\pi$ & $\begin{array}{c}-0.747 \\
(-1.052,-0.441)\end{array}$ & $<0.001^{\star \star \star}$ & $\begin{array}{c}-0.784 \\
(-1.111,-0.457)\end{array}$ & $<0.001^{\star * \star}$ & - & - & - & - \\
\hline APTा & $\begin{array}{c}-0.992 \\
(-1.865,-0.119)\end{array}$ & $0.026^{*}$ & $\begin{array}{c}-1.062 \\
(-1.983,-0.140)\end{array}$ & $0.024^{*}$ & - & - & - & - \\
\hline Globulin & $\begin{array}{c}1.746 \\
(0.664,2.828)\end{array}$ & $0.013^{*}$ & $\begin{array}{c}1.523 \\
(0.354,2.692)\end{array}$ & $0.011^{*}$ & - & - & - & - \\
\hline Respiratory infection & - & - & - & - & $\begin{array}{c}2.711 \\
(1.558,4.718)\end{array}$ & $<0.001^{\star \star \star}$ & $\begin{array}{c}2.677 \\
(1.462,4.901)\end{array}$ & $0.001^{* *}$ \\
\hline
\end{tabular}

* $\mathrm{P}<0.05$; ${ }^{* *}, \mathrm{P}<0.01$; ${ }^{* *}, \mathrm{P}<0.001$. Model 1 was unadjusted; Model 2 was further adjusted for air pressure, relative humidity, wind speed and air quality index. $\mathrm{Cl}$, confidential interval; SBP, systolic blood pressure; DBP, diastolic blood pressure; TT, thrombin time; APTT, activated partial thromboplastin time; WBC, white blood cell; OR, odds ratio.

Previous studies indicated some possible mechanisms. During exposure to a hot environment, the body needs to increase heat diffusion via sweating, which could engender dehydration. Dehydration may increase the risk of microvascular thrombosis and subsequent ischemic stroke by increasing the blood viscosity (5). In our study, the reduced TT and APTT in patients exposed to heatwaves suggested that extremely high temperatures affect the coagulation system and increase fibrinolysis, which is in line with a previous finding that exposure to heat could reduce APTT. However, there was no clear description of the biological mechanism responsible for the changes in the coagulation system (27). It has been considered that the platelet activation induced by hot temperatures, which leads to secondary activation of coagulation factors or endothelial cells, may be responsible for the alterations in 
the coagulation system (28).

Both the long- and short-term effects of temperatures on blood pressure have been extensively researched. The majority of these studies assumed a linear relationship between temperature and blood pressure and found that decreased temperatures were associated with increased blood pressure $(29,30)$. However, few studies have investigated the effect of hot temperatures on blood pressure, and those that have done so have produced controversial findings $(31,32)$. Different studies exploring the relationship between heatwaves and hypertension admissions have also reached contradictory conclusions $(12,33)$.

Our study revealed that heatwaves were associated with elevated blood pressure at admission, possibly due to the involvement of several biological mechanisms. First, when exposed to extremely high temperatures, the body needs to increase heat diffusion through sweating. The production of large amounts of sweat affects the levels of micronutrients, which are closely related to blood pressure $(12,34)$. Second, high temperatures can lead to oxidative stress, inflammation, and endothelial dysfunction, which are all associated with hypertension $(6,34)$. Besides, exposure to heatwaves may disrupt human sleep patterns and insufficiency of sleep is closely related to elevated blood pressure $(5,35)$.

Cold temperatures could also lead to vasoconstriction and subsequent elevation of blood pressure. In our study, the elevated blood pressure of participants exposed to cold spells was consistent with previous findings $(23,30,32)$. Some thrombogenic factors-such as fibrinogen level, platelet aggregation, blood cell count, and CRP-increase in response to exposure to cold, which increases the risk of brain ischemia $(6,15)$. A recent study found that risk factors and coagulation factors for ischemic stroke patients admitted during cold periods differed from those of patients admitted on warmer days (22). The TT refers to the time of blood clotting after the addition of standardized thrombin to the plasma, indicating the function of the endogenous blood coagulation system. Reduced TT is often found in patients in a hypercoagulable state $(22,36)$. In our study, cold spells were associated with a high level of fibrinogen and shorter TT, suggesting that exposure to cold spells promoted a hypercoagulable state, which is closely related to the occurrence and poor prognosis of ischemic stroke $(6,23)$.

Studies have suggested that ischemic stroke patients admitted during winter experience poorer outcomes than those admitted in other seasons (37). In our study, ischemic stroke patients who were exposed to cold spells displayed elevated inflammatory indices (including increased white blood cell count and globulin level) at admission, and were also more likely to develop respiratory infection during hospitalization. The most obvious explanation for this is that influenza is more common in cold weather, and ischemic stroke patients are particularly vulnerable to complications associated with influenza infections such as pneumonia (38). A number of randomized control trials and cohort studies have demonstrated that influenza vaccination is significantly associated with a lower risk and better outcome in ischemic stroke patients $(38,39)$. However, compared with that in developed countries, the rate of influenza vaccination is much lower in mainland China, which could also contribute to the high level of respiratory infections after exposure to cold (40). Additionally, a cold ambient temperature was associated with an increase in circulating biomarkers of inflammation, which could result in a hypercoagulable state. And in our study we also found that patients exposed to cold spells showed reduced TT and increased fibrinogen, which strongly predict cardio-cerebrovascular events $(21,22)$. As a result, exposure to cold may potentially affect vasoconstriction, systemic inflammation, and thrombus formation as constituent of mechanisms leading to ischemic stroke. Further prospective studies are needed to confirm the findings of this study.

Several limitations exist in our study. First, the data were from a single center; therefore, there may have been some selection biases which impacted the results. For instance, the lack of a significant difference in NIHSS scores among groups at admission may have been due to selection bias. Further multicenter studies are required to more comprehensively explore the effects of extreme temperatures on ischemic stroke patients. Second, the 24-hour average outdoor temperature was used as the definition of a heatwave or cold spell. However, during extreme weather conditions, people often spent more time indoors. As a result, the effect of exposure to heatwaves and cold spells may have been underestimated, with the effects actually happening in response to a shorter exposure time. Third, we were unable to assess all relevant variables, and the candidate variables selected in our study were mostly in accordance with those used in previous studies $(5,23)$. Last, as our center is located in a warm-temperate, semi-humid, monsoon climate zone, our results may differ from those of other regions with more varied climatic conditions and socio-economic characteristics.

\section{Conclusions}

The study explored the effects of exposure to heatwaves 


\section{Page 10 of 12}

and cold spells on the blood pressure, thrombotic factors, and inflammatory indices of patients with ischemic stroke at admission. The results showed that both heatwaves and cold spells had an effect on blood pressure and the coagulation system. Besides, a higher proportion of patients exposed to cold spells had respiratory infection and a higher level of inflammation. These findings suggested that extreme temperatures may affect cerebrovascular disease by contributing to changes in blood pressure, coagulation, and/or inflammation. Further prospective studies are needed to confirm these findings. Study of the effects of extreme temperatures on ischemic stroke could enable better management of patients with ischemic stroke and exposure to extreme temperatures. Therefore, it would be of great significance to construct a more accurate heatwave and cold-spell warning system.

\section{Acknowledgments}

Funding: This work was supported by the Major Social Science Program of Tianjin Municipal Education Commission (2017JWZD36), Key Technology Research and Development Program of Science and Technology, Tianjin (18ZXDBSY00210), Research and Promotion Project of Appropriate Technology for Intervention of High Risk Population of Stroke in China (2020R0005), Clinical Medicine Research Project of the Second University of Tianjin Medical University (2020LC04), and Key Subject of Tianjin Health Committee (15KG136).

\section{Footnote}

Reporting Checklist: The authors have completed the STROBE reporting checklist. Available at http://dx.doi. org/10.21037/atm-20-4256

Data Sharing Statement: Available at http://dx.doi. org/10.21037/atm-20-4256

Conflicts of Interest: All authors have completed the ICMJE uniform disclosure form (available at http://dx.doi. org/10.21037/atm-20-4256). The authors have no conflicts of interest to declare.

Ethical Statement: The authors are accountable for all aspects of the work in ensuring that questions related to the accuracy or integrity of any part of the work are appropriately investigated and resolved. The study was conducted in accordance with the Declaration of Helsinki (as revised in 2013). The study was approved by the Ethics Committee of the Second Hospital of Tianjin Medical University (KY2020K142), and the requirement for individual consent for this retrospective analysis was waived. Open Access Statement: This is an Open Access article distributed in accordance with the Creative Commons Attribution-NonCommercial-NoDerivs 4.0 International License (CC BY-NC-ND 4.0), which permits the noncommercial replication and distribution of the article with the strict proviso that no changes or edits are made and the original work is properly cited (including links to both the formal publication through the relevant DOI and the license). See: https://creativecommons.org/licenses/by-nc-nd/4.0/.

\section{References}

1. GBD 2016 DALYs and HALE Collaborators. Global, regional, and national disability-adjusted life-years (DALYs) for 333 diseases and injuries and healthy life expectancy (HALE) for 195 countries and territories, 1990-2016: a systematic analysis for the Global Burden of Disease Study 2016. Lancet 2017;390:1260-344. Erratum in: Lancet. 2017 Oct 28;390(10106):e38. doi: 10.1016/ S0140-6736(17)32648-X. Epub 2017 Oct 13.

2. Wang W, Jiang B, Sun H, et al. Prevalence, Incidence, and Mortality of Stroke in China: Results from a Nationwide Population-Based Survey of 480687 Adults. Circulation 2017;135:759-71.

3. Han J, Liu S, Zhang J, et al. The impact of temperature extremes on mortality: a time-series study in Jinan, China. BMJ Open 2017;7:e014741.

4. Guan W, Clay SJ, Sloan GJ, et al. Effects of Barometric Pressure and Temperature on Acute Ischemic Stroke Hospitalization in Augusta, GA. Transl Stroke Res 2018. [ Epub ahead of print]. doi:10.1007/s12975-018-0640-0.

5. McArthur K, Dawson J, Walters M. What is it with the weather and stroke? Expert Rev Neurother 2010;10:243-9.

6. Chen R, Wang C, Meng X, et al. Both low and high temperature may increase the risk of stroke mortality. Neurology 2013;81:1064-70.

7. Guo Y, Gasparrini A, Armstrong BG, et al. Heat Wave and Mortality: A Multicountry, Multicommunity Study. Environ Health Perspect 2017;125:087006.

8. Phung D, Thai PK, Guo Y, et al. Ambient temperature and risk of cardiovascular hospitalization: An updated systematic review and meta-analysis. Sci Total Environ 2016;550:1084-102. 
9. Yang J, Yin P, Zhou M, et al. The burden of stroke mortality attributable to cold and hot ambient temperatures: Epidemiological evidence from China. Environ Int 2016;92-93:232-8.

10. Dawson J, Weir C, Wright F, et al. Associations between meteorological variables and acute stroke hospital admissions in the west of Scotland. Acta Neurol Scand 2008;117:85-9.

11. Gronlund CJ, Sullivan KP, Kefelegn Y, et al. Climate change and temperature extremes: A review of heatand cold-related morbidity and mortality concerns of municipalities. Maturitas 2018;114:54-9.

12. Sherbakov T, Malig B, Guirguis K, et al. Ambient temperature and added heat wave effects on hospitalizations in California from 1999 to 2009. Environ Res 2018;160:83-90.

13. Royé D, Zarrabeitia MT, Riancho J, et al. A time series analysis of the relationship between apparent temperature, air pollutants and ischemic stroke in Madrid, Spain. Environ Res 2019;173:349-58.

14. Cowperthwaite MC, Burnett MG. An analysis of admissions from 155 United States hospitals to determine the influence of weather on stroke incidence. J Clin Neurosci 2011;18:618-23.

15. Chen JH, Jiang H, Wu L, et al. Association of ischemic and hemorrhagic strokes hospital admission with extreme temperature in Nanchang, China-A case-crossover study. J Clin Neurosci 2017;43:89-93.

16. Luo Y, Li H, Huang F, et al. The cold effect of ambient temperature on ischemic and hemorrhagic stroke hospital admissions: A large database study in Beijing, China between years 2013 and 2014-Utilizing a distributed lag non-linear analysis. Environ Pollut 2018;232:90-6.

17. Goggins WB, Woo J, Ho S, et al. Weather, season, and daily stroke admissions in Hong Kong. Int J Biometeorol 2012;56:865-72.

18. Guo P, Zheng M, Wang Y, et al. Effects of ambient temperature on stroke hospital admissions: Results from a time-series analysis of 104,432 strokes in Guangzhou, China. Sci Total Environ 2017;580:307-15. Erratum in: Sci Total Environ. 2017 Oct 1;595:1. doi: 10.1016/ j.scitotenv.2017.03.193. Epub 2017 Mar 31.

19. Gao J, Yu F, Xu Z, et al. The association between cold spells and admissions of ischemic stroke in Hefei, China: Modified by gender and age. Sci Total Environ 2019;669:140-7.

20. Emsley HC, Smith CJ, Gavin CM, et al. An early and sustained peripheral inflammatory response in acute ischaemic stroke: relationships with infection and atherosclerosis. J Neuroimmunol 2003;139:93-101.

21. Schäuble CL, Hampel R, Breitner S, et al. Short-term effects of air temperature on blood markers of coagulation and inflammation in potentially susceptible individuals. Occup Environ Med 2012;69:670-8.

22. Cai J, Meng X, Wang C, et al. The cold effects on circulatory inflammation, thrombosis and vasoconstriction in type 2 diabetic patients. Sci Total Environ 2016;568:271-7.

23. Chen X, Shang W, Huang X, et al. The Effect of Winter Temperature on Patients with Ischemic Stroke. Med Sci Monit 2019;25:3839-45.

24. Xie H, Yao Z, Zhang Y, et al. Short-term effects of the 2008 cold spell on mortality in three subtropical cities in Guangdong Province, China. Environ Health Perspect 2013;121:210-6.

25. Kim EJ, Kim H. Effect modification of individualand regional-scale characteristics on heat wave-related mortality rates between 2009 and 2012 in Seoul, South Korea. Sci Total Environ 2017;595:141-8.

26. Wang L, Liu T, Hu M, et al. The impact of cold spells on mortality and effect modification by cold spell characteristics. Sci Rep 2016;6:38380.

27. Meyer MA, Ostrowski SR, Overgaard A, et al. Hypercoagulability in response to elevated body temperature and central hypovolemia. J Surg Res 2013;185:e93-100.

28. Strother SV, Bull JM, Branham SA. Activation of coagulation during therapeutic whole body hyperthermia. Thromb Res 1986;43:353-60.

29. Hintsala H, Kandelberg A, Herzig KH, et al. Central aortic blood pressure of hypertensive men during shortterm cold exposure. Am J Hypertens 2014;27:656-64.

30. Su D, Du H, Zhang X, et al. Season and outdoor temperature in relation to detection and control of hypertension in a large rural Chinese population. Int J Epidemiol 2014;43:1835-45.

31. Kim YM, Kim S, Cheong HK, et al. Effects of heat wave on body temperature and blood pressure in the poor and elderly. Environ Health Toxicol 2012;27:e2012013.

32. Madaniyazi L, Zhou Y, Li S, et al. Outdoor Temperature, Heart Rate and Blood Pressure in Chinese Adults: Effect Modification by Individual Characteristics. Sci Rep 2016;6:21003

33. Zheng S, Wang M, Shang K, et al. A case-crossover analysis of heat wave and hospital emergency department visits for cardiovascular diseases in 3 hospitals in Beijing. 
Wei Sheng Yan Jiu 2016;45:246-51.

34. Tang YM, Wang DG, Li J, et al. Relationships between micronutrient losses in sweat and blood pressure among heat-exposed steelworkers. Ind Health 2016;54:215-23.

35. Obradovich N, Migliorini R, Mednick SC, et al. Nighttime temperature and human sleep loss in a changing climate. Sci Adv 2017;3:e1601555.

36. Pelz JO, Harms K, Metze M, et al. Spontaneous cervical artery dissection is accompanied by a hypercoagulable state and simultaneous inflammatory condition. J Neurol 2018;265:308-14.

37. Liu Y, Gong P, Wang M, et al. Seasonal variation of admission severity and outcomes in ischemic stroke - a consecutive hospital-based stroke registry. Chronobiol Int
2018;35:295-302.

38. Tsivgoulis G, Katsanos AH, Zand R, et al. The association of adult vaccination with the risk of cerebrovascular ischemia: A systematic review and meta-analysis. J Neurol Sci 2018;386:12-8.

39. Lam F, Chen TL, Shih CC, et al. Protective effect of influenza vaccination on outcomes in geriatric stroke patients: A nationwide matched cohort study. Atherosclerosis 2019;282:85-90.

40. Wang Q, Yue N, Zheng M, et al. Influenza vaccination coverage of population and the factors influencing influenza vaccination in mainland China: A meta-analysis. Vaccine 2018;36:7262-9.
Cite this article as: Qi X, Wang Z, Xia X, Xue J, Gu Y, Han S, Yao Q, Cai Z, Wang X, Wang L, Leng SX, Li X. The effects of heatwaves and cold spells on patients admitted with acute ischemic stroke. Ann Transl Med 2021;9(4):309. doi: 10.21037/ atm-20-4256 